\title{
Novo Nordisk invests in academic diabetes research
}

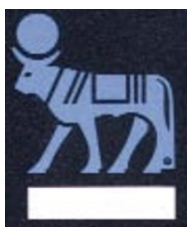

Britain's National Health Service (NHS) is teaming up with a university and a pharmaceutical company to build a $\$ 16$ million center for research and treatment in diabetes and other hormonal and metabolic diseases. The partners hope that by bringing clinicians, academics and patients under one roof, they will ensure that scientists ask the right questions, and that clinicians both influence the research and act promptly on its findings.

The Oxford Centre for Diabetes, Endocrinology and Metabolism, which will open by 2001, brings together six of Oxford University's biomedical and clinical research teams working in diabetes and other hormone-related conditions, such as osteoporosis. The center expects to handle some 15,000 outpatient contacts per year. It will employ around 150 researchers and clinicians, and will offer teaching and specialist training. The diabetes research will focus on areas in which Oxford is already strong, such as the genetics of the disease, the mechanisms of $\beta$-cell failure, and large-scale clinical trials of treatments.

The university's diabetes researchers have collaborated with the pharmaceutical company Novo Nordisk, Europe's largest supplier of insulin, for 20 years, and it was they who approached the company to help fund the proposed center. But despite investing 40 percent of the total cost of setting up the

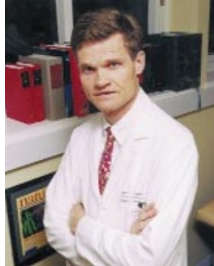
John Bell apeutic molecules, it is understandable that its expectations from Oxford are different. However, some observers believe that Novo Nordisk's management may not be unanimous in backing such an openended commitment. One commentator suggested that there was "a battle within the organization" between the company's senior, traditionally philanthropic leadership and middle managers that want targets and hard returns on investment. But publicly at least, the com-

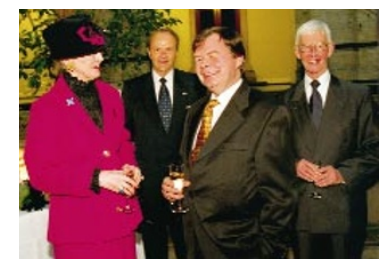

Queen Margrethe II of Denmark meets representatives from the Karolinska Institute and Novo Nordisk participation in the center.

The mastermind behind the center is Nuffield Professor of Clinical Medicine at Oxford John Bell, who is also chairman of the partnership board. Bell hopes it will stimulate "a renaissance of clinically based, bedside research, fuelled by the pany insists it favors the move whole-heartedly and sees no conflict between what it calls "good neighbourliness" and its long-term business strategy.

"We see it as a natural development," says Stig Pramming, senior medical director at Novo Nordisk's Danish headquarters. Oxford's reputation for diabetes research makes it an obvious choice within Europe, he says. "We believe we are the best diabetes company in the world...if we are going to be competitive in the future we need to stay with the best and pick up the best ideas as fast as possible."

The biggest financial backer, however, is the NHS itself, which is putting in 42 percent of the cost of the center. Health service managers increasingly need data on the cost-effectiveness of treatments and care regimens, and they will be looking to the center for the kind of research that informs health policy-known in the trade as 'outcomes data.' Pramming thinks the NHS should be credited with "being visionary and taking an international view" for its molecular revolution." He says the reductionist approach of identifying genes and molecules implicated in human disease has worked "fantastically well," but that it is now time to add translational research to the effort. "It's great to work with a knockout mouse," he says, "but if you have a human with exactly that gene defect down the hall, it's interesting to know what the phenotype of that disease is."

Shortly after the initiative was announced, Novo Nordisk's largest shareholder, the Novo Nordisk Foundation, announced separately that it was giving $\$ 16$ million to a consortium of Scandinavian researchers to investigate the vascular biology of diabetes complications such as nephropathy and blindness. The Foundation is separate from the company, although the company's board of directors are members of the Foundation's governing body.

Ironically, although the Oxford center is emphasizing the importance of putting clinicians and researchers under one roof in the hopes that they will swap ideas over coffee, the Scandinavian consortium is entirely virtual, linked only by e-mail and a generous travel budget. It would be "old-fashioned" to have everyone in one building, says Karl Tryggvason, the consortium's lead investigator, at the Karolinska Institute in Stockholm.

Phyllida BROWN, LONDON may emerge, and intellectual property rights will remain with the principal investigators.

What Novo Nordisk is getting for its money, says David Matthews, previously director of diabetes and endocrinology at Oxford's Radcliffe Infirmary and now the center's chairman, is a close association with a world-class research effort and the University of Oxford's credentials. There will be collaboration so that each partner can influence the others' ideas, but if the company wants to guarantee specific rights to any discoveries, it will have to commission a project just like any other client.

As Novo Nordisk already has large commercial research bases for identifying ther-

\section{No-consent trials raise concern}

Data from a trial of a whole blood substitute that was suspended one year ago, has revealed a higher mortality among patients receiving the substitute than those receiving saline. The substitute, HemAssist, made by Baxter Healthcare was administered to subjects admitted to emergency rooms and experiencing severe blood loss, under a controversial 1996 Food and Drug Administration (FDA) protocol that allows testing without the direct consent of patients. Of four studies operated under this rule, twoincluding the HemAssist trial-have recently been terminated, renewing concern that individuals are being exposed to risk without informed consent. The dropped trials have also caused anxiety among researchers that corporate sponsors will avoid such studies in the future.

The rule was intended to facilitate research in emergency medicine, in which patients arrive unconscious at hospital and decisions must be made rapidly. Under the system, products can be tested without patients' consent, but only if stringent requirements are met to inform 